\title{
Combining pharmacophore- and MD-based modelling for phase II metabolism prediction
}

\author{
Christin Rakers", Gerhard Wolber \\ From 9th German Conference on Chemoinformatics \\ Fulda, Germany. 10-12 November 2013
}

As metabolism is considered a main cause for adverse drug reactions and failures of new drug candidates, our goal is to establish an in silico method to efficiently predict phase II metabolism - in particular sulfotransferase (SULT) activity. Since sulfotransferases exhibit low substrate specificities caused by their high degree of conformational freedom [1], activity prediction is a challenging task.

We therefore established a workflow based on molecular dynamics (MD) simulations to cover the whole spectrum of structural flexibility and incorporated it into multiple pharmacophores that represent specific modes of action. Using an ensemble of pharmacophores for virtual screening ensures accurate categorization of potential SULT ligands (e.g. substrates, inhibitors). Recent advances in MD technology [2] allowed for refinement of these pharmacophores by high-throughput MD simulations of ligand-target complexes. In addition, the initial binding process of a soluble ligand to the substrate-binding site of SULT was captured in unbiased 100 ns simulations using the software Desmond [3].

Published: 11 March 2014

\section{References}

1. Dong D, Ako R, Wu B: Crystal structures of human sulfotransferases: insights into the mechanisms of action and substrate selectivity. Expert Opin Drug Metab Toxicol 2012, 8:635-646.

2. Dror $\mathrm{RO}$, et al: Biomolecular simulation: a computational microscope for molecular biology. Annu Rev Biophys 2012, 41:429-452.

3. Bowers KV, et al: Scalable Algorithms for Molecular Dynamics Simulations on Commodity Clusters. SC 2006 Conference, Proceedings of the ACM/IEEE 2006.

\footnotetext{
* Correspondence: christin.rakers@fu-berlin.de

Computer-Aided Drug Design, Pharmaceutical and Medicinal Chemistry, Institute of Pharmacy, Freie Universität Berlin, 14195 Berlin, Germany
}

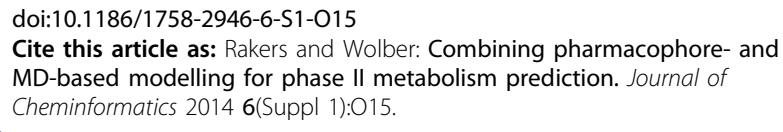

Cite this article as: Rakers and Wolber: Combining pharmacophore- and MD-based modelling for phase II metabolism prediction. Journal of Cheminformatics 2014 6(Suppl 1):015.

\section{Publish with ChemistryCentral and every scientist can read your work free of charge \\ "Open access provides opportunities to our colleagues in other parts of the globe, by allowing anyone to view the content free of charge." \\ W. Jeffery Hurst, The Hershey Company. \\ - available free of charge to the entire scientific community \\ - peer reviewed and published immediately upon acceptance \\ - cited in PubMed and archived on PubMed Central \\ - yours - you keep the copyright \\ Submit your manuscript here: \\ http://www.chemistrycentral.com/manuscript/

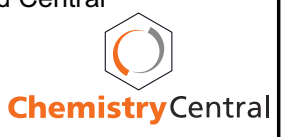

